Dublin, Ireland

\title{
Pedagogical Competencies - An Analysis of Learning Outcomes of the Program for Acquiring Pedagogical Competencies within Lifelong Learning in the Republic of Croatia
}

\author{
${ }^{1}$ Renata Burai, ${ }^{2}$ Rona Bušljeta Kardum \\ ${ }^{1}$ Assistant Professor, Academy of Fine Arts of University of Zagreb \\ ${ }^{2}$ Assistant Professor, Faculty of Croatian Studies, University of Zagreb
}

\begin{abstract}
Education has long been recognized as the key to the survival not only of the individual but of society as a whole. Today we are facing numerous challenges that require some new knowledge and skills from the individual. The education system, i.e. teachers, have a key role in enabling an individual to have ready answers to the challenges of the 21 st century. The importance and necessity of quality teacher training has been recognized by numerous European and Croatian documents, with recommendations based on various scientific research. The aim of this paper is to single out the key competencies of teachers and with their help to analyse the learning outcomes of some of the current lifelong learning programs for the acquisition of pedagogical competencies in the Republic of Croatia. The conducted analysis will determine whether the pedagogical competencies are developed during the compulsory part of the program for the acquisition of pedagogical competencies, or whether they are acquired during the elective courses. The obtained results will indicate whether there is a need to design and implement a unique program at a national level that would ensure the acquisition of basic pedagogical competencies for all teachers after the completion of the program.
\end{abstract}

Keywords: competences; lifelong learning; learning outcomes; pedagogical courses; teachers. 